\title{
SOCIO-EDUCATIONAL CORRELATES OF BULLYING IN THE SCHOOL CONTEXT
}

\author{
Simona Butnaru ${ }^{1}$
}

\begin{abstract}
Bullying is an increasingly common problem in schools, associated with negative educational outcomes for both bullies and victims. This study explored the socio-educational family and school variables related to bullying, victimization and positive behavior, such as age, gender, separation from parents, school results, and truancy. In this study 311 students ( $50.8 \%$ boys) have participated, they were aged between 6 and 16 years $(M=11.01, S D=1.71)$, enrolled in primary school $(47.3 \%)$ and in secondary school $(52.7 \%)$, all were from urban areas. $43.8 \%$ of respondents were separated from one or both parents due to divorce (17.4\%), parental death $(6.1 \%)$, migration $(20 \%)$ or abandonment $(0.3 \%)$. Bullying, victimization and positive behavior were measured with one standardized scale; the data about school results and attendance of the students was collected from the school registers; family information was self-reported by participants. Because Cronbach's Alpha for the positive behavior scale was 0.57 , lower that 0.7 , this scale was not considered for further data analysis. Empirical data for the study was collected before the outbreak of the COVID-19 pandemic.

The Mann-Whitney $U$ test showed significant age differences: secondary school students scored higher in aggression than primary school students. We also found significant gender differences in bullying behavior: boys' reported higher level of aggression. The Independent Sample Student's t-test indicated gender differences in school results: the boys obtained lower school results in Language and Mathematics than the girls. Separation from one or both parents did not lead to significant differences in bullying behavior, but pupils separated from their parents had fewer school absences than their colleagues not separated from their parents. Pearson's correlation indicated that students with higher bullying scores, also scored higher on victimization and had higher number of school absences, but had scored lower grades in Language and Mathematics. Oneway ANOVA indicated that victimization was influenced by age and bullying was influenced by gender. Also, one-way ANOVA indicated an effect of bullying on school results. Two-way ANOVA showed an interaction effect between gender and separation from parents on bullying. When living with both parents, boys had higher bullying scores, but under separation condition, the boys scored slightly lower than girls. The implications of the results for education and counseling are discussed.
\end{abstract}

UDC Classification: 37.06, DOI: https://doi.org/10.12955/pss.v2.203

Keywords: bullying, victimization, separation from parents, truancy, school outcomes

\section{Introduction}

Since the 1980s, with the early research of Norwegian professor Dan Olweus which used the terms of bully and victim in the school context, a large number of books and articles have been written on this subject, as this phenomenon is widespread throughout the world and has long-term negative effects on the personal and social development of young people (Crick, 1996, Olweus, 1993, Smith et al., 2011, Lodder et al., 2016, Blakely-McClure \& Ostrov, 2016 etc.). Bullying has been recognized as a violation of the United Nations Convention on the Rights of the Child to a safe learning environment at school (Olweus, 1993). Olweus affirmed that a student is being bullied or victimized when he or she is exposed, repeatedly and over time, to negative actions on the part of one or more students. These actions can include physical, verbal or relational aggression such as being hit, beaten, threatened or locked up etc. (Crick, 1996, Hamburger et al. 2011; Olweus 1993). A condition of bullying is the asymmetric power relationship between bully and victim which is somewhat helpless against the student or students who harass (Olweus 1993, p. 10). It is not bullying when two equally strong students quarrel, fight or tease each other (Solberg \& Olweus, 2003).

\section{Factors associated with bullying in school}

The literature review provides evidence that there are many social conditions representing risk factors for bullying, such as age, gender, race, and belongingness to a minority group etc. Bozan et al. (2021) bring evidence that bullying is higher among older students and students who don't like the school. Also, these authors claim that family-related variables influence the bullying behavior of the students, such as students who are separated from their parents and those who witness and experience violence within their families scored higher on bullying. Montero-Carretero et al. (2021) indicated that the controlling style of teachers during physical education classes increases frustration and positively predicts bullying.

Many recent studies endorse the protective role of certain aspects of the school climate (e.g. sense of belongingness to school, quality of friendship, cooperation, teacher-student relationship centered on

\footnotetext{
${ }^{1}$ Alexandru Ioan Cuza University of Iasi, Faculty of Psychology and Educational Sciences, Department of Educational Sciences, Iasi, Romania, simona.butnaru@uaic.ro
} 
students' autonomy) and family climate (e.g. warm parent-child relationship) against bullying and its negative effects (Arslan, 2021; Chen et al.; 2021, Chen \& Wei, 2013; Schacter et al., 2021; MonteroCarretero et al., 2021; Zhao et al., 2021; Zhang et al., 2021). In a preadolescent's sample, Arslan (2021) find that students with higher levels of sense of belonging had higher school achievement and reported lower school bullying. Also, Chen et al. (2021) evidenced the protective role of the sense of belongingness to school in the relationship between peer victimization, school truancy and life satisfaction, in an international sample of adolescents from Western and East Asian Countries. Montero-Carretero et al. (2021) indicate that bullying can be reduced through physical education programs centered on self-determination, autonomy, cooperation and reflection on the anguish that someone may experience in the schoolyard when he or she feels cornered or on whether individual differences justify harassing someone. In a systematic literature review, Schacter et al. (2021) suggest that the quality of friendship moderates in many ways the effects of bullying on negative health outcomes. Thus, some reviewed studies indicated that friendship is a protective factor that can mitigate bullying-related harm, whereas other highlighted that friendship can amplify victimization-related distress. Studies on junior high and high school students indicate the protective role of the parent-child relationship against bullying (Sevcikova, et al., 2015; Zhao et al., 2021; Zhang et al., 2021) and that this role is more important for younger students (Zhao et al., 2021). Sevcikova et al. (2015) argue that strong child-parent attachment increases social support seeking when adolescents are exposed to bullying.

In addition, studies show the important role of internal subjective factors in reducing the negative effects of bullying on school outcomes and subjective well-being (school and life satisfaction) (Oriol et al., 2021). In a longitudinal study, Oriol et al. (2021) show that the experience of gratitude helps students to maintain stable levels of life satisfaction regardless of the prevalence of cyberbullying after six months.

\section{Effects of bullying on educational outcomes}

Based on previous empirical studies on the negative effects of bullying on short and long-term achievements, meta-analyses by Samara et al. (2021) and Ttofi et al. (2011) point out the increased short-term risks of bullying like school absenteeism, truancy and dropout rate for the students who perceive the school as an unsafe place and also, long-term risk of bullying to develop adverse outcomes, later in their life. Ttofi et al. (2011) endorse the importance of quality anti-bullying prevention programs to interrupt future criminal careers.

Chen \& Wei (2013) find that victimization by peers is strongly related to maltreatment by teachers, the victimization negatively predict the perception of social support from peers and social support is a powerful predictor of students' psychological health. The authors show that the relationship between victimization, social support and psychological health is stronger for girls than for boys.

\section{Present study}

This study explored the influence of socio-educational family and school variables such as age, gender, separation from parents, school results, and truancy on bullying, victimization and positive behavior of the students.

The study assumed significant gender and age differences in bullying and victimization behaviors, in the sense that boys and older students are more intensely involved than girls and younger students, respectively. It also assumed that the students who are experiencing parental separation will have a more intense involvement in bullying, both as victims and as aggressors. Another hypothesis of our study was that the involvement in bullying behaviors will negatively correlate with learning outcomes and appropriate behavior in the school and positively correlate with truancy. The study aimed to explore the interaction effects between gender and separation from parents on bullying, victimization and positive behavior.

\section{Method}

\section{Participants}

In this study, 311 students (50.8\% boys) have participated. They were aged between 6 and 16 years ( $M$ $=11.01, S D=1.71), 47.3 \%$ of the students were enrolled in the primary schools, and all the respondents were from urban areas. One hundred and thirty-six students $(43.7 \%)$ were separated from 
one or both parents due to divorce (17.4\%), parental death $(6.1 \%)$, migration $(20 \%)$ or abandonment $(.3 \%)$.

\section{Instruments}

Bullying, victimization and positive behavior were measured through a scale of Stevens, Van Oost and Bourdeaudhuij (2000), adapted to Romanian by Beldean-Galea and Jurcău (2010). This instrument is based on a 5-point Likert scale with 22 items ranging from 1 (almost not at all) to 5 (very often). Bullying behavior was measured with 8 items (e.g. How often have you insultingly nicknamed other students?), victimization with 8 items (e.g. How often have other students threatened you?), and positive behavior with 6 items (e.g. How often have other colleagues talked to you about their interests?). Beldean-Galea and Jurcău (2010) reported Cronbach's Alpha coefficients of .81 for bullying, .63 for victimization and .72 for positive behavior. Relatively different Cronbach's alpha coefficients were reported for this sample: aggression (.73), victimization (.83) and positive behavior (.57). Because of the value of Cronbach's alpha for positive behavior scale (.57), it was not considered for further data analysis. Based on items scores, a mean score for each scale was calculated.

School outcomes and attendance records were collected from the school registers. In the Romanian secondary education system, school outcomes are evaluated through grades ranged from 1 (very poor) to 10 (very good). Assessment in primary education is expressed by qualitative grades, "insufficient", "sufficient", "good" and "very good". To process data about student achievement in the same way, we recoded the qualitative grades into numerical values: "insufficient" was recoded as 4, "sufficient" as 6, "good" as 8 and "very good" as 10.

Information about the structure of the family of origin, the condition and the reason for the separation from parents was self-reported by participants.

The age variable was coded in two categories: primary school and secondary school.

\section{Procedure}

Data were collected during the school program, based on voluntary involvement and parental consent, before the outbreak of the COVID-19 pandemic.

\section{Statistical analyses}

For testing the relationships between independent variables (gender, age, separation from parents) and dependent variables we used both parametric and nonparametric tests, because some of the dependent variables had a normal distribution (Math and Language grades and victimization) and other (school absences and bullying behavior) did not. As shown in Table 1, the data has a normal distribution for the Math and Language grades and victimization. For these variables, the skewness and kurtosis ranged between -1.00 and +1.00 . Gender, separation and age-related differences in school grades and victimization were calculated with a parametric test - Independent Samples Student's $t$-test. The data for the school absences and bullying were not normally distributed. Mann-Whitney $U$ nonparametric tests were performed to evaluate gender, separation and age-related differences in school absences and bullying behavior.

To evaluate the effects of age, gender and separation from parents on school results, bullying and victimization, one-way ANOVA was performed. Interaction effects between gender and separation from parents on aggressive behavior were measured with two-way ANOVA.

The relationships between bullying/victimization behavior and school outcomes were tested with Pearson's correlation.

\begin{tabular}{|c|c|c|c|c|c|c|c|c|}
\hline & $n$ & Minimum & Maximum & Mean & $\begin{array}{l}\text { Standard } \\
\text { Deviation }\end{array}$ & Median & Skewness & Kurtosis \\
\hline Math & 299 & 3.00 & 10.00 & 7.53 & 1.76 & 8.00 & -.35 & -.88 \\
\hline Language & 299 & 4.00 & 10.00 & 7.79 & 1.58 & 8.00 & -.47 & -.52 \\
\hline $\begin{array}{l}\text { School } \\
\text { Absences }\end{array}$ & 154 & 0 & 102 & 5.53 & 11.52 & 1.50 & 4.91 & 33.6 \\
\hline Bullying & 311 & 1.00 & 5.00 & 1.56 & .69 & 1.37 & 2.07 & 7.08 \\
\hline Victimization & 310 & 1.00 & 5.00 & 2.21 & .96 & 2.00 & .87 & .25 \\
\hline
\end{tabular}




\section{Results}

Mann-Whitney $U$ test indicated significant gender and age differences in bullying behavior and school absences. Specifically, boys scored higher in bullying than girls $\left(U=9625.00, p<.01, M R_{\text {boys }}=\right.$ $\left.171.58, M R_{\text {girls }}=139.91\right)$. Secondary school pupils scored higher in bullying $(U=10473.00, p<.05$, $M R_{\mathrm{sec}}=165.64, M R_{\text {prim }}=145.24$, ) and more school absences than primary school pupils $U=1462.00$, $\left.p<.05, M R_{\text {prim }}=63.16, M R_{\text {sec }}=81.11\right)$.

We did not find significant differences in bullying $\left(U=10862.00, p>.05, M R_{\text {sep }}=151.02, M R_{\text {nonsep }}=\right.$ $159.13)$ and in the number of school absences $\left(U=2647.00, p>.05, M R_{\text {sep }}=73.89, M R_{\text {nonsep }}=81.72\right)$ between students who are separed from one or both parents and students who are living with both parents.

Independent samples $t$-test showed significant gender, age and separation related differences in school outcomes. Girls obtained better school results than boys in Math $(t(290.88)=-2.57, p=.01, d=-.28)$ and Language $(t(257.78)=-2.91, p<0.01, d=-.33)$. The respondents from primary schools obtained betters school outcomes (Math: $t(297)=5.54, p=.00, d=.61$, Language: $(t(297)=5.50, p=.00, d=$ $.60)$ and had lower scores in victimization $(t(308)=-2.28, p<.05, d=-.25)$ than the respondents from secondary schools $(t(308)=-1.1, \mathrm{p}>0.05)$

Pearson's correlations (see Table 2) indicated that bullying was positively associated with victimization and with school absences and negatively associated with school outcomes in Math and Language. Victimization was positively correlated with bullying and negatively with Language results.

\begin{tabular}{|c|c|c|c|c|c|c|}
\hline & & Math & Language & School absences & Bullying & Victimization \\
\hline \multirow{2}{*}{ Math } & & 1 & $.77^{* *}$ & $-.28^{* *}$ & $-.18^{* *}$ & $\begin{array}{l}.08 \\
-.08\end{array}$ \\
\hline & $n$ & 299 & 299 & 151 & 299 & 298 \\
\hline \multirow[t]{2}{*}{ Language } & & $.77^{* *}$ & 1 & $-.37^{* *}$ & $-.24^{* *}$ & $-.18^{* *}$ \\
\hline & $n$ & 299 & 299 & 151 & 299 & 298 \\
\hline \multirow[t]{2}{*}{ School absences } & & $-.28^{* *}$ & $-.37^{* *}$ & 1 & $.19^{*}$ & .10 \\
\hline & $n$ & 151 & 151 & 154 & 154 & 154 \\
\hline \multirow{2}{*}{ Bullying } & & $-.18^{* * *}$ & $-.24^{* *}$ & $.19^{*}$ & 1 & $.36^{* *}$ \\
\hline & $n$ & 299 & 299 & 154 & 311 & 310 \\
\hline \multirow[t]{2}{*}{ Victimization } & & -.08 & $-.18^{* *}$ & .10 & $.36^{* * *}$ & 1 \\
\hline & $n$ & 298 & 298 & 154 & 310 & 310 \\
\hline
\end{tabular}

\begin{tabular}{|lcccccc|}
\hline \multicolumn{7}{|c|}{ Table 3. Two-way Anova - effects of gender and separation from parents on bullying } \\
\hline & $\begin{array}{c}\text { Type III Sum of } \\
\text { Squares }\end{array}$ & $\boldsymbol{d f}$ & Square & $\boldsymbol{F}$ & Sig. & $\begin{array}{c}\text { Partial Eta } \\
\text { Squared }\end{array}$ \\
\hline Corrected Model & $4,505^{\mathrm{a}}$ & 3 & 1.502 & 4.294 & .005 & .040 \\
Intercept & 693,185 & 1 & 693.185 & 1982.240 & .000 & .866 \\
gender & 1,318 & 1 & 1.318 & 3.770 & .053 & .012 \\
separation & 0,048 & 1 & .048 & .137 & .711 & .000 \\
gender * separation & 2,131 & 1 & 2.131 & $\mathbf{6 . 0 9 3}$ & $\mathbf{. 0 1 4}$ & .019 \\
Error & 107,357 & 307 & .350 & & & \\
Total & 846,922 & 311 & & & & \\
Corrected Total & 111,862 & 310 & & & & \\
\hline a. $R$ Squared $=.040$ (Adjusted $R$ Squared $=.031)$ \\
\hline Source: Author
\end{tabular}

A one-way ANOVA results indicated a principal effect of age on victimization $(F(1,306)=5.72, p<$ $\left..05, \eta=.27, M_{\text {prim }}=2.08, S D=.88, M_{\mathrm{sec}}=2.32, S D=1.00\right)$ and of gender on bullying $(F(1,307)=$ $\left.14.07, p=.00, \eta=.14, M_{\text {girls }}=1.45, S D=.57, M_{\text {boys }}=1.62, S D=.61\right)$. Students enrolled in secondary school reported higher victimization and boys scored high in bullying.

We divided the sample into two categories based on the median value of bullying scores: with a low level of aggression (scores below 1.37 - the median value) and with a high level of aggression (scores 
above the median value). Bullying had a significant negative effect on Language $(F(15,28)=2.7, p<$ $\left..05, \eta=.37, M_{\text {low }}=8.19, S D=1.39, M_{\text {high }}=7.43, S D=1.64\right)$ and on Math outcomes $(F(15,28)=$ $\left.2.18, p<.05 \eta=.32, M_{\text {low }}=7.83, S D=1.74, M_{\text {high }}=7.26, S D=1.75\right)$. Students with higher scores in bullying had lower grades.

As shown in Table 3, two-way ANOVA indicated an interaction effect between gender and separation from parents on bullying in this sample $(F(1,307)=6.09, p<0.05)$. Results suggest that when living with both parents, boys had higher bullying scores than girls, but under separation condition, the boys scored slightly less than girls (see Figure 1).

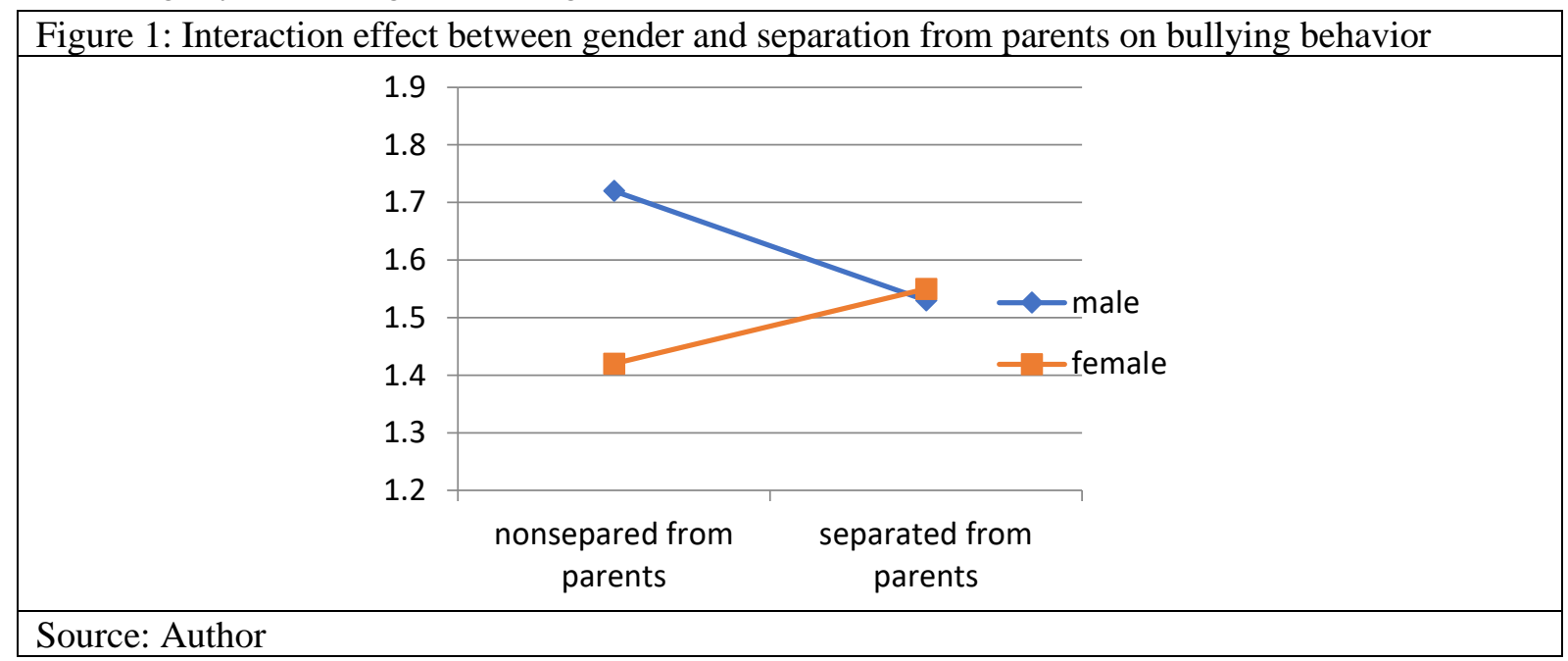

\section{Discussion}

This study provided evidence for the socio-educational correlates of bullying and victimization experiences in the school context. The results of the study confirm the results from previous studies (Bozan et al., 2021) that older students are more involved in bullying than younger students. Unlike Bozan et al. (2021); Zhao et al. (2021); Zhang et al., (2021) who supported the idea that separation from parents predisposes to experience bullying, in our sample, there were no significant differences in bullying and victimization between children who are separated from one or both parents and children who are living with both parents. Probably, there are many other family-related variables, such as violence and gender-related expectations that can explain bully attitude in boys living with both parents.

Our results confirm the research indicating that girls obtain higher school grades and have fewer school absences than boys (Gherasim et al., 2012).

Other expected results of this study highlight age-related differences in school achievement: secondary school students had lower grades and more absences, because of change in the school climate and increasing challenges related to the more complex and difficult school tasks (Butnaru \& Gherasim, 2014).

The negative effects of bullying and victimization documented by empirical studies (Lodder et al., 2016, Blakely-McClure \& Ostrov, 2016 etc.) and meta-analyses in this field (Samara et al., 2021) are confirmed through our data which indicated that bullies had lower school achievement and they miss several days from school than their colleagues. In our sample, victimization correlated negatively with achievement in language. The bully's attitude is stronger and more diverse associated with poor school results than the victim's attitude. A strong positive association has been found between aggression and victimization which suggests that relatively many students have experienced both bullying roles: victim and bully.

An important result of this research is the significant interaction between gender and separation from parents as factors of bullying in school. Unlike Bozan et al. (2021), who argue that separation from parents is an explanatory factor for increasing bullying, our findings suggest this relationship depends on the child's gender. Boys living with both parents are more involved in bullying than girls. In the condition of separation from one or both parents, boys are less and girls are more aggressive, being slightly more aggressive than boys. 


\section{Conclusion}

Based on the results of this study, separation from parents does not explain bullying, victimization, and school outcomes, but the interaction between separation from parents and gender explain bullying. Bullying was negatively related to school outcomes and positively related to victimization and truancy, while victimization was negatively related to language grades. Our data suggest that antibullying counselling and education programs are needed for schools and families to ensure safer environments for pupils in school and to limit children's exposure to aggressive behavior patterns in schools and families.

One limitation of this study is that it did not consider other family-related issues that may impact bullying and victimization, in addition to separation from parents, such as parenting style or childparent attachment. Also, classroom climate variables, such as social support from teachers and colleagues, and subjective variables, such as school expectations could be included in future studies about the socio-educational correlates of bullying in the school context.

\section{References}

Arslan, G. (2021). School Bullying and Youth Internalizing and Externalizing Behaviors: Do School Belonging and School Achievement Matter? International Journal of Mental Health and Addiction, DOI: 10.1007/s11469-021-00526-X.

Beldean-Galea I.-E. \& Jurcău N. (2010). Studiul calităţilor psihometrice ale unui chestionar de evaluare a fenomenului "bullying" la elevi [Study of the psychometric qualities of a questionnaire to evaluate the phenomenon of "bullying" in students]. Romanian Journal of Applied Psychology, 12(1), 15-20.

Blakely-McClure, S.J., \& Ostrov, J.M. (2016). Relational aggression, victimization and self-concept: Testing pathways from middle childhood to adolescence. Journal of Youth and Adolescence, 45, 376-390. DOI 10.1007/s10964-015-0357-2.

Bozan, K., Evgin, D., \& Beser, N.G. (2021). Relationship of bullying in adolescent period with family functionalities and child behaviors. Psychology in the Schools, 58(8), 1451-1473. DOI: 10.1002/pits.22501.

Chen, I.H., Gamble, J.H., \& Lin, C.Y. (2021). Peer victimization's impact on adolescent school belonging, truancy, and life satisfaction: A cross-cohort international comparison. Current Psychology, 1-18. DOI: 10.1007/s12144-021-01536-7.

Chen, J-K. \& Wei, H.-S. (2013). School violence, social support and psychological health among Taiwanese junior high school students. Child Abuse \& Neglect, 37(4), 252-262. DOI: 10.1016/j.chiabu.2013.01.001.

Crick, N. R. (1996). The role of overt aggression, relational aggression, and prosocial behavior in the prediction of children's future social adjustment. Child Development, 67, 2317-2327. DOI: 10.1111/j.1467-8624.1996.tb01859.x.

Gherasim, L. R., Butnaru, S., \& Măirean, C. (2012). Classroom environment, achievement goals and maths performance: gender differences. Educational Studies, 39(1), 1-12. DOI: 10.1080/03055698.2012.663480.

Hamburger M. E., Basile K. C., Vivolo A. M. (2011). Measuring Bullying Victimization, Perpetration, and Bystander Experiences: A Compendium of Assessment Tools. Atlanta, GA: Centers for Disease Control and Prevention, National Center for Injury Prevention and Control.

Lodder, G. M. A., Scholte, R. H. J., Cillessen, A. H. N., \& Giletta, M. (2016). Bully victimization: Selection and influence within adolescent friendship networks and cliques. Journal of Youth and Adolescence, 45, 132-144. DOI: 10.1007/s10964015-0343-8.

Montero-Carretero, C., Roldan, A., Zandonai, T., \& Cervelló, E. (2021). A-Judo: An Innovative Intervention Programme to Prevent Bullying Based on Self-Determination Theory-A Pilot Study. Sustainability, 13(5), 2727. DOI: $10.3390 / \mathrm{su} 13052727$.

Oriol, X., Varela, J., \& Miranda, R. (2021). Gratitude as a Protective Factor for Cyberbullying Victims: Conditional Effects on School and Life Satisfaction. International Journal of Environmental Research. Public Health, 18, 2666. DOI: 10.3390/ijerph18052666

Samara, M., Da Silva Nascimento, B., El-Asam, A., Hammuda, S., \& Khattab, N. (2021). How Can Bullying Victimisation Lead to Lower Academic Achievement? A Systematic Review and Meta Analysis of the Mediating Role of CognitiveMotivational Factors. International Journal of Environmental Research. Public Health, 18, 2209. DOI: https://doi.org/10.3390/ ijerph18052209.

Schacter, H.L., Lessard, L.M., Kiperman, S., Bakth, F., Ehrhardt, A., \& Uganski, J. (2021). Can friendships protect against the health consequences of peer victimization in adolescence? A systematic review, 13(3), 578-601. School Mental Health. DOI: $10.1007 / \mathrm{s} 12310-021-09417-x$.

Sevcikova, A., Machackova, H., Wright, M.F., Dedkova, L. \& Cerna, A. (2015). Social Support Seeking in Relation to Parental Attachment and Peer Relationships Among Victims of Cyberbullying. Journal of Psychologists and Counsellors in Schools, 25(2) , 170-182. DOI: 10.1017/jgc.2015.1.

Smith, P. K., Morita, Y., Junger Tas, J., Olweus, D., Catalano, R., \& Slee P. (2011). The Nature of School Bullying. A crossnational perspective. New York, NY: Routledge.

Solberg, M. E., \& Olweus, D. (2003). Prevalence estimation of school bullying with the Olweus Bully Victim Questionnaire. Aggressive Behavior. 29, 239-268. 
Stevens, V., Van Oost, P., \& De Bourdeaudhuij, I. (2000). The effects of an anti-bullying intervention programme on peers' attitudes and behaviour. Journal of Adolescence, 23(1), 21-34. DOI:10.1006/jado.1999.0296.

Olweus, D. (1993). Bullying at school : what we know and what we can do. Oxford, UK: Blackwell Publishing.

Ttofi, M.T., Farrington, D. P., Lösel, F. \& Loeber, R. (2011). The predictive efficiency of school bullying versus later offending: A systematic/meta-analytic review of longitudinal studies. Criminal Behaviour and Mental Health, 21(2), 8089. DOI: $10.1002 / \mathrm{cbm} .808$.

Zhang, M., Wang, Z., Persram, R.J., Wong, T.K.Y., \& Konishi, C. (2021). Perceived Social Support From Family and Peers: The Association With Bullying Behaviours. Journal of Education and Development, 5(1), 17-29.

DOI:10.20849/jed.v5i1.835.

Zhao, Y.P., Hong, J.S., Zhao, Y.F., \& Yang, D.L. (2021). Parent-child, teacher-student, and classmate relationships and bullying victimization among adolescents in China: Implications of school mental health. School Mental Health, 13, 644654. DOI: -10.1007/s12310-021-09425-x. 